Kinaschuk $M$.

\title{
DEVELOPMENT OF METHOD OF TESTING A SET OF SCREEN-EXHAUST DEVICES IN THE HELICOPTER Mi-8MSB-B
}

The object of research is a set of screen-exhaust devices (SED) as part of the Mi-8MSB-Vhelicopter (Ukrainian version of the modernization of the Soviet multipurpose Mi-8 helicopter, developed by Motor Sich JSC, Zaporizhzhia, Ukraine). The SED set is designed to reduce the infrared signature of helicopters equipped with TV3-117 turboshaft engines of all modifications for the Mi-8MSB-V, Mi-8MT, Mi-14 and Mi-24.

One of the problem areas is the lack of methods for solving the problem of determining the parameters and tactical and technical characteristics when examining SED as part of an aircraft during testing and research, which must be carried out in accordance with the approved Technical Operation Manual.

When constructing the developed methodology, the rules of the Technical Operation Manual and the Helicopter Flight Operation Manual were applied, which allows testing in compliance with flight safety standards. Flight tests serve as a source of information for analytical calculations, the SED models and verification of their reliability by checking the convergence of the parameters of the functioning process under the same conditions using simulation and flight experiments.

The developed technique of research and testing of a set of screen-exhaust devices makes it possible to check the performance of a specific sample in all flight modes. The technique makes it possible to determine the level of engine power losses in different operating modes using the parameters of the on-board information collection facilities in conjunction with SED. This makes it possible to obtain a characteristic of fuel consumption in the case of a set of screen-exhaust devices installed on board and without it. The technique takes into account the possibility of simultaneously conducting both flight and ground tests of SED to construct an infrared radiation indicatrix and determine the distances and angles of target capture by the homing head of portable anti-aircraft missile systems.

Analysis of the data obtained made it possible to determine the direction of further computational and experimental studies aimed at improving the flow path of the SED.

Keywords: screen-exhaust device, infrared radiation, Mi-8MSB-V helicopter, flight modes, fuel consumption.

\section{Introduction}

The use of screen-exhaust devices (SED) in gas turbine engines (GTE) of helicopters is one of the effective means of passive protection against damage by missiles with thermal homing. Reducing the temperature of the GTE exhaust gases of by $30 \%$ reduces the range of capture by optoelectronic systems by $43 \%$, and a decrease in their temperature by $50 \%$ reduces the range of capture by $67 \%$ [1]. The use of portable anti-aircraft missile systems has exacerbated the problem and made it one of the topical in modern conditions. Over the past more than 40 years, more advanced ejection-type SEDs have been developed. The helicopters of the Mi-8 family are currently using SEDs of the Soviet design (Fig. 1) [2] and the modern Ukrainian «Quadros» (Fig. 2) [3].

The ejection effect makes it possible to reduce the temperature to $200{ }^{\circ} \mathrm{C}$. One of the advantages of the ejector is the absence of moving parts, as well as the ability to work for a long time in a hot aggressive environment - the exhaust gas of a gas turbine engine. Therefore, the relevance of the study lies in the essential sense of ensuring the survivability of military helicopters.

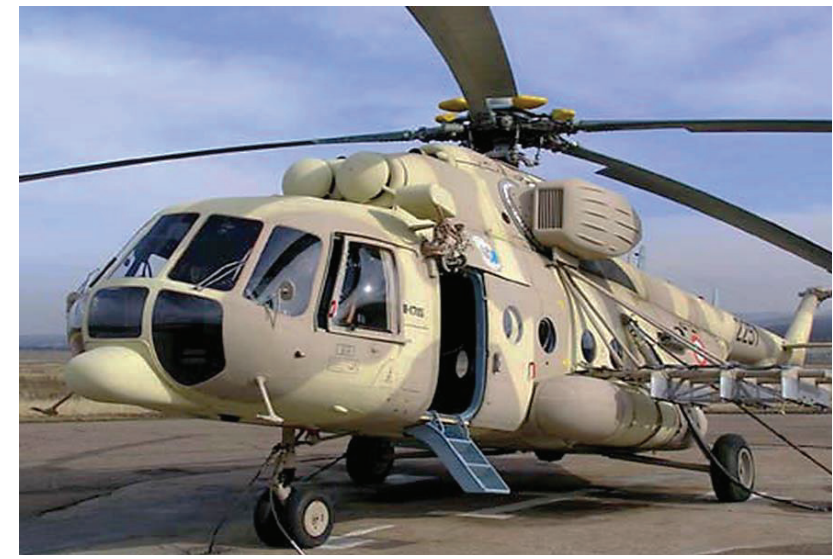

Fig. 1. Screen-exhaust devices of the Soviet production [2] 


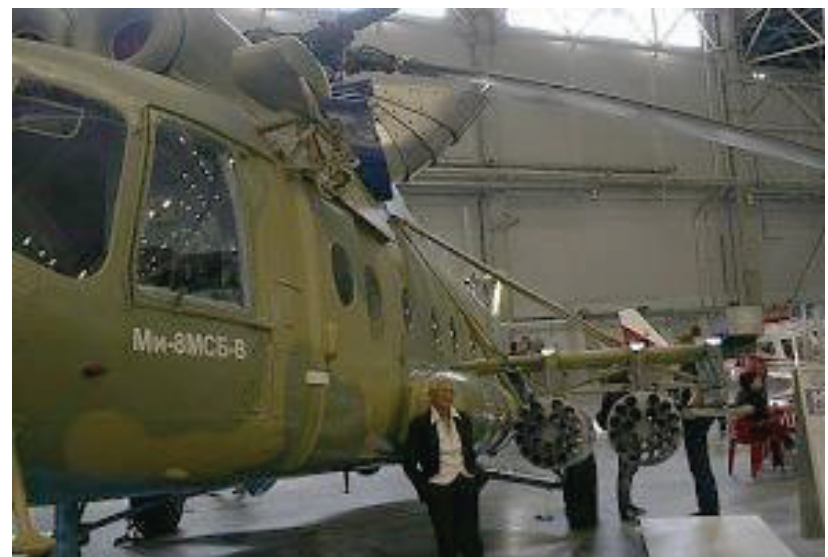

Fig. 2. Screen-exhaust devices of Ukrainian design «Quadros» [3]

\section{The object of research and its technological audit}

The object of research is a set of screen-exhaust devices (SED) as part of the Mi-8MSB-V helicopter (Ukrainian version of the modernization of the Soviet multipurpose Mi-8 helicopter, developed by Motor Sich Joint Stock Company, Zaporizhzhia, Ukraine).

The SED set is designed to reduce the infrared signature of helicopters equipped with TV3-117 turboshaft engines of all modifications for the Mi-8MSB-V, Mi-8MT, Mi-14 and Mi-24. SED designs for the right and left engines of the helicopter are completely identical, in a mirror image.

One of the problem areas is the lack of methods for solving the problem of determining the parameters and tactical and technical characteristics when examining SED as part of an aircraft during testing and research, which must be carried out in accordance with the approved Technical Operation Manual.

\section{The aim and objectives of research}

The aim of research is to develop an effective method for collecting and registering parametric information for analyzing the functionality of the developed SED set as part of the Mi-8MSB-V helicopter.

To achieve this aim, it is necessary to complete the following objectives:

1. Conduct an analysis of the existing and standard on-board measuring instruments (OMI) in order to ensure the registration of the necessary parameters for assessing the characteristics of the investigated SED.

2. Develop a test procedure for a SED set as part of the Mi-8MSB-V helicopter.

\section{Research of existing solutions of the problem}

Today, man-portable anti-aircraft missile systems (MANPADS) with homing heads ( $\mathrm{HH}$ ) have become one of the most effective and widespread means of combating aircraft, helicopters and other air targets in the conduct of hostilities. However, their widespread use for terrorist purposes has greatly exacerbated the problem of the flight safety of civilian aircraft and helicopters, making it one of the most acute and important in modern conditions.
Therefore, a new and promising direction for ensuring the safety of air transport is the creation of systems for protecting aircraft from possible damage by missiles with infrared homing heads.

Recently, the leading countries of the world have been taking measures to improve HH systems, expand the areas of application of the $\mathrm{HH}$ spectrum band of anti-aircraft guided missiles.

So, in work [4] the analysis of modern guided means of destruction of aircraft of the leading militarily countries of the world and their counteraction - onboard complexes of protection of aircraft is carried out. The need for passive protection of aircraft from infrared radiation was also noted, but examples of the effectiveness of such measures and parametric information were not given.

In [5], the sources of the infrared signature of a helicopter in flight are shown, schematic design solutions of the SED used by the leading manufacturers of combat helicopters are shown. The qualitative indicators of the SED use effectiveness for shielding the heated surfaces of the GTE output devices are presented. However, the recommendations developed by the authors can only be used at the stage of future design solutions for projects of new combat helicopters.

The authors of the studies [6], based on the results of numerical modeling, proposed different orientations in the direction of exhaust gas discharge; structurally, they should be provided with different angles of installation on board the helicopter. The authors assume that the intensity of the level of infrared radiation will vary depending on the angle of the direction of the exhaust gases. However, the results of these studies can't be fully analyzed, since the authors did not provide input data for the numerical simulations.

In work [7], a method of shielding the exhaust system of a gas turbine engine with the analysis of the infrared signature of the system «exhaust tract - screen-exhaust device» is proposed. A numerical study was carried out taking into account the geometric dimensions, aerodynamic and gas-dynamic characteristics of the SED with imitation in flight. And the main places of the helicopter's infrared radiation were considered by the authors of [8]. The authors paid great attention to the background of thermal radiation of the fuselage skin elements from the engines located under the hood. But the author did not consider the means of passive protection.

With regard to SED field tests as part of a helicopter and the methodology of these tests, their need for obtaining reliable research results is indicated in $[9,10]$. However, the authors do not fully describe the methodology, algorithm or sequence of such tests.

Due to the specifics of the SED use and the high cost of carrying out field tests, the authors of research on this topic limit themselves only to numerous studies of developed or promising SED schemes. And the tactical and technical characteristics of the investigated SED schemes are not given. An exception is the work [11], the author of which proposed new approaches to solving the survivability of the aircraft, including through the SED integration into the power plant of the proposed new design of the combat helicopter.

In many studies, only the results of theoretical studies or experimental results of model tests are considered. So, in [12], algorithmic and software are presented 
that implements a developed method for determining the characteristics of a subsonic gas ejector of a gas turbine engine. The geometrical parameters of the subsonic gas ejector have been calculated and a bench model has been created for experimental research.

The work [13] presents the results of research under the program «Establishment of statistical characteristics of the repeatability of loads on units in normal operation» and the program of certification factory tests «Establishment of the main operational and technical characteristics of a helicopter engine with a screen-exhaust device». However, quantitative or qualitative results are not listed, only the names of assessments of compliance with certification requirements are listed.

All the above works make it possible to solve the problems of numerical modeling of SED and calculation of their design parameters. Methods for calculating ejector-type output devices for various applications and highly efficient experimental samples of ejector-type output devices have also been developed. But the methods for solving the problem of determining the parameters and tactical and technical characteristics in the SED study in the composition of an aircraft are absent in the literature, which makes the study promising.

\section{Methods of research}

5.1. Analysis of available and standard on-hoard measurement equipment (OMI) of flight information. To ensure the assessment of the level of infrared radiation (IR radiation) of a helicopter with an installed SED set and check the temperature conditions of their operation, it is proposed to use equipment as part of:

- radiometer of the IR radiation receiver of the homing head of the R-60 type air-to-air guided missile (Vympel aircraft plant, Tbilisi, Georgia). Sensitivity

in the wavelength range $\Delta \lambda=2.8-4.2$ microns);

- devices for control, indication and registration of radiometer signals: millivoltmeter V3-38 (Tallinn plant «Punane-RET», Estonia), laptop;

- thermal imager «testo 875-2i» (Testo AG, Germany) and an autonomous power source.

The onboard measurement system should ensure the registration of parameters according to the lists given in Table 1.

List of parameters recorded by standard on-board measurement equipment

Table 1

\begin{tabular}{|c|c|c|c|c|c|c|}
\hline No. & Parameter name & Symbol & Unit & Measurement range & Sensor type & Sampling frequency, $\mathrm{Hz}$ \\
\hline 1 & Barometric altitude & $H$ & Meter & $0 \ldots 6000$ & DV $15 \mathrm{MV}$ & 2 \\
\hline 2 & Flight speed & $V_{f s}$ & $\mathrm{~km} / \mathrm{h}$ & $0 \ldots 450$ & DAС-27 & 2 \\
\hline 3 & Dutside air temperature & $T_{o}$ & ${ }^{\circ} \mathrm{C}$ & $-60 \ldots+60$ & $\mathrm{P}-1$ & 2 \\
\hline 4 & Main rotor pitch & $\varphi_{o p}$ & Degree & $0 . .15$ & MU 615A & 4 \\
\hline 5 & Main rotor revolutions & $N_{m r}$ & $\%$ & $0 \ldots 110$ & D-2MT & 4 \\
\hline 6 & Left engine turbocharger speed & $N_{t c l}$ & $\%$ & $0 \ldots 110$ & D-2MT & 4 \\
\hline 7 & Right engine turbocharger speed & $N_{t c r}$ & $\%$ & $0 \ldots 110$ & D-2MT & 4 \\
\hline 8 & $\begin{array}{l}\text { Gas temperature behind the turbine } \\
\text { compressar of the left engine }\end{array}$ & $T_{g l}$ & ${ }^{\circ} \mathrm{C}$ & $0 \ldots 1000$ & Thermocouple T-80T & 4 \\
\hline 9 & $\begin{array}{l}\text { Gas temperature behind the turbine } \\
\text { compressor of the right engine }\end{array}$ & $T_{g r}$ & ${ }^{\circ} \mathrm{C}$ & $0 . .1000$ & Thermocouple T-80T & 4 \\
\hline 10 & Left engine fuel consumption & $G_{f l}$ & $\mathrm{~km} / \mathrm{h}$ & $0 . .600$ & TDR-8-1-1 & 4 \\
\hline 11 & Right engine fuel consumption & $G_{f r}$ & $\mathrm{~km} / \mathrm{h}$ & $0 \ldots 600$ & TDR-8-1-1 & 4 \\
\hline 12 & Bolls & G & Degree & $-50 \ldots+50$ & AGB-3K & 4 \\
\hline 13 & Pitch & $v$ & Degree & $-50 \ldots+50$ & AGB-3K & 4 \\
\hline 14 & Dverload & $\begin{array}{l}n_{x} \\
n_{y} \\
n_{z}\end{array}$ & $g$ & $\begin{array}{l}-1.5 \ldots+1.5 \\
-1.0 \ldots+3.0 \\
-1.5 \ldots+1.5\end{array}$ & MP-95 & 4 \\
\hline 15 & $\begin{array}{l}\text { Longitudinal position of the handle of } \\
\text { the cyclic pitch }\end{array}$ & $X_{1}$ & $\mathrm{~mm}$ & $-180 \ldots+180$ & MU-615A & 4 \\
\hline 16 & $\begin{array}{l}\text { Transverse position of the handle of } \\
\text { the cyclic pitch }\end{array}$ & $X_{t}$ & $\mathrm{~mm}$ & $-180 \ldots+180$ & MU-615A & 4 \\
\hline 17 & Travel pedal travel & $X_{p}$ & $\mathrm{~mm}$ & $-100 \ldots+100$ & MU-615A & 4 \\
\hline 18 & $\begin{array}{l}\text { Dil pressure at the entrance to the left } \\
\text { engine }\end{array}$ & $P_{e l}$ & $\mathrm{~kg} / \mathrm{cm}^{2}$ & $0 \ldots 30$ & IMD-8 & 4 \\
\hline 19 & $\begin{array}{l}\text { Dil pressure at the entrance to the } \\
\text { right engine }\end{array}$ & $P_{e l}$ & $\mathrm{~kg} / \mathrm{cm}^{2}$ & $0 . .30$ & IMD-8 & 4 \\
\hline 20 & Left engine compartment temperature & $T_{c l}$ & ${ }^{\circ} \mathrm{C}$ & $-60 \ldots+200$ & Thermocouple* & 2 \\
\hline 21 & Right engine compartment temperature & $T_{c r}$ & ${ }^{\circ} \mathrm{C}$ & $-60 \ldots+200$ & Thermocouple* & 2 \\
\hline
\end{tabular}

Note: * - layouts of thermocouples for measuring the temperature in the engine compartment are developed by the customer for testing SED 
To determine the amount of power loss on the shaft of a free turbine of a helicopter GTE, as one of the main indicators of the SED efficiency, the following parameters are required:

- barometric flight altitude;

- flight speed;

- outside air temperature;

- gas temperature behind the compressor turbine of the left and right engines;

- fuel consumption of the left and right engines;

- temperature of the engine compartment of the left and right engines.

These parameters and their characteristics are recorded by OMI.

For further research, it is necessary to develop a test methodology for a set of screen-exhaust devices as part of the Mi-8MSB-V helicopter.

This methodology will determine the general conditions and procedure for testing the SED set as part of the Mi-8MSB-V helicopter.

When constructing this methodology, the Technical Operation Manual and the Helicopter Flight Manual will be used; algorithms and methods of information processing proposed by the author and criteria for evaluating the SED technical characteristics when working together with the engine.

The described methodology determines the general conditions and procedure for conducting research and preliminary tests (hereinafter referred to as PT) of the SED set as part of the Mi-8MSB-V helicopter.

5.2. Test procedure for a set of screen-exhaust devices in the Mi-8MSB-V helicopter

5.2.1. During the tests, the tactical and technical characteristics of the SED set are carried out under the specified conditions of the impact of external factors of a natural nature, as well as on the specified operating modes of the test object. During the tests, it is necessary to use the methods for assessing the compliance of the SED set with the requirements of the TA (technical assignment for experimental design work «Development of a set of screen-exhaust devices for turboshaft engines of the TV3-117 type»):

At the stage of ground tests:

- calculations - when assessing changes in the characteristics of the range and duration of a helicopter flight, associated with the installation of a SED set;

- engineering analysis - when assessing the sufficiency of the materials provided, confirming the structural strength of the EEC research set (calculations, certificates, conclusions);

- assessment of the technical level of the SED set. At the stage of flight tests:

- experimental determination of the thrust characteristics of a helicopter with a SED set for evaluating the power losses of engines;

- experimental determination of the characteristics of the infrared radiation of a helicopter with a SED set to assess the degree of reduction in the strength of infrared radiation from the output devices of the engines.

For direct measurement of the thrust force of the helicopter, the thrust characteristics are determined by the method of changing the take-off mass of the helicopter in hover modes in the zone and outside the zone of influence of the air cushion effect.

Hovering modes are performed at heights of 2, 4, 6, 8, $10,15,20,25,35 \mathrm{~m}$ at three values of the helicopter take-off weight, which is determined by the fueling option (main tanks and additional ones). Hover height control is carried out by the onboard technician using a measuring halyard.

When determining the thrust characteristics of a helicopter, all hover modes are performed against the wind at the same or close wind speed and outside air temperature.

The tests are carried out during the day, in simple weather conditions. The working conditions must correspond to the operating conditions of the helicopter.

The evaluation of the design and operational documentation of the SED set is carried out by the test team. Let's also check the completeness, layout and quality of installation of a set of electric power supplies, an assessment of their external condition. The calculation of the mass data of the helicopter is carried out with various options for refueling, range and duration of the flight with an experimental SED set.

For the greatest reliability of the results of comparing the obtained parameters of the engines and the temperature of the environment, it is advisable to carry out tests under the same atmospheric conditions (temperature and pressure of atmospheric air, wind speed and direction). Parameters are recorded by means of on-board measuring instruments (OMI).

5.2.2. Measurement of the strength of infrared radiation of the output devices of engines. SED set is designed to reduce the infrared signature of helicopters equipped with TV3-117 turboshaft engines of all modifications for the Mi-8MSB-V, Mi-8MT, Mi-14 and Mi-24. The designs of the screen-exhaust devices for the right and left engines of the helicopter are completely identical, in the mirror image they are performed by measuring and constructing a circular indicatrix of the IR radiation strength. To exclude the influence of the reflected solar radiation of the IR radiation of the helicopter, the work should be performed in cloudy weather in the absence of rain, snow, fog. In the direction from the ground equipment for measuring the magnitude of the strength of infrared radiation within an angle of $\pm 20^{\circ}$ vertically and horizontally, there should be no sources of infrared radiation of natural and artificial origin (the sun, powerful electric lamps, heating electrical appliances, etc.).

Ground equipment for measuring the strength of infrared radiation should be located at a distance of $300 \mathrm{~m}$ from the helicopter.

The indicator of the magnitude of the strength of infrared radiation is taken in five positions of the ground equipment for measurement relative to the helicopter:

- at angles of orientation of the helicopter to ground

equipment to measure the magnitude of the IR radiation force $20^{\circ}, 45^{\circ}, 90^{\circ}, 135^{\circ}, 160^{\circ}$ (Fig. 3);

- in each position, the engine is set to the following modes: cruising, maximum long-term, takeoff.

During the tests, it is necessary to ensure the synchronization (time reference) of the data received from the OMI recorders. The progress of the tests is recorded by photo and video equipment.

To check the operation of the power plant and OMI with an installed SED set, the flight is performed at a wind speed of up to $5 \mathrm{~m} / \mathrm{s}$ in the following sequence:

- to launch and test engines in accordance with the Flight Operations Manual (FOM) of the Mi-8MSB-V helicopter; 
- taxiing to the take-off site, perform a control hover at a height of $3-5 \mathrm{~m}$;

- at a hovering height of $3-5 \mathrm{~m}$, check the operation of engines;

- perform two turns while hovering $360^{\circ}$ to the right and to the left with an angular speed of no more than $12 \%$ s; - accelerate with a gradual climb so as to reach at an altitude of $20-30 \mathrm{~m} V_{r}=50-60 \mathrm{~km} / \mathrm{h}$;

- upon reaching $V_{r}=120 \mathrm{~km} / \mathrm{h}$, transfer the helicopter to climb;

- at an altitude of $500 \mathrm{~m}$, transfer the helicopter to level flight at speed $V_{r}=120-130 \mathrm{~km} / \mathrm{h}$;

- accelerate to $V_{r}^{\max }$, decelerate to $V_{r}^{\min }$, left and right bends and with a roll of $30^{\circ}$ at speed $V_{r}=120 \mathrm{~km} / \mathrm{h}$;

- carry out motor gliding to a height of $H=120 \mathrm{~m}$;

- to hover on $H=120 \mathrm{~m}$;

- transfer the helicopter to acceleration to $V_{r}=120 \mathrm{~km} / \mathrm{h}$ without a helicopter drawdown;

- fly around the measuring base $H=120 \mathrm{~m}$ and $V_{r}=$ $=120 \mathrm{~km} / \mathrm{h}$;

- perform a helicopter landing;

- taxiing, cool down and turn off the engines.

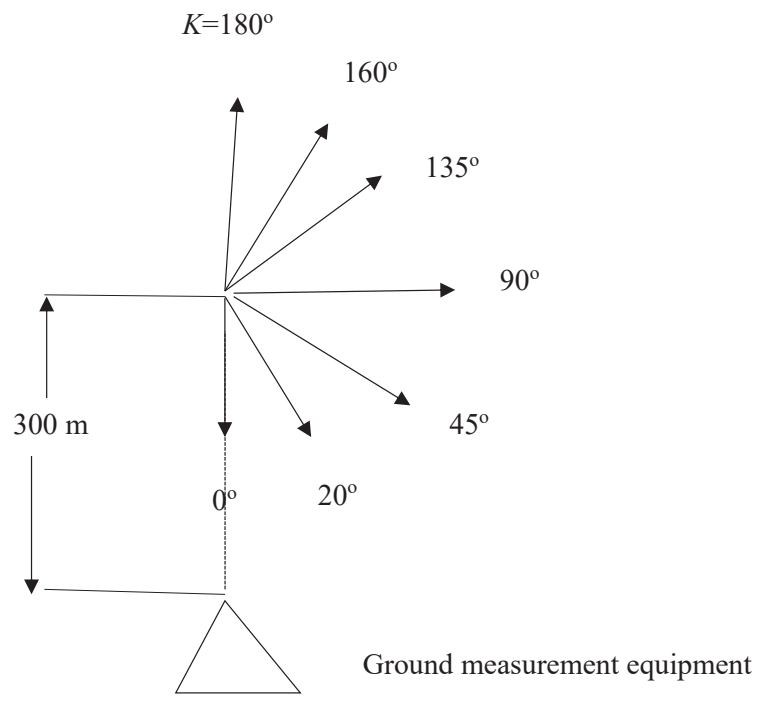

Fig. 3. Layout of control points for recording the strength of infrared radiation

After processing and analyzing the flight data, the performance of the helicopter systems and the power plant with a SED set is evaluated.

Evaluation of traction characteristics of a helicopter with a SED set is performed in hover mode at an altitude of $3-5,10,25,35 \mathrm{~m}$ at a wind speed of up to $5 \mathrm{~m} / \mathrm{s}$. Takeoff weight should be $9000 \mathrm{~kg}, 11100 \mathrm{~kg}$ and $12500 \mathrm{~kg}$ (or the maximum allowable for meteorological conditions according to nomograms). The operating parameters of the motors must comply with the Manual for the Technical Operation (MTO) of engines of TV3-117VMA-SBM1V 4E series (MTO).

Checking the magnitude of the power of infrared radiation during horizontal flight with a SED set.

The magnitudes of the strength of infrared radiation are measured in various conditions of use of the helicopter, namely:

a) flight stages - take-off, climb, level flight, descent, approach and landing; b) flight modes - steady flight at a constant speed, maneuvering in horizontal and vertical planes;

c) flight altitude - in the range of altitudes $H=10-50 \mathrm{~m}$;

d) flight speed - in the range of $V_{r}=100-200 \mathrm{~km} / \mathrm{h}$

e) flight range - depending on the infrared sensitivity of the seeker (IR seeker);

f) takeoff weight $-m_{t}=10800-11000 \mathrm{~kg}$.

5.2.3. Determination of the height of the practical ceiling of the helicopter, the time of climb with kilometer fuel consumption SED set. The flight to the service ceiling is performed as follows: before takeoff, using the graph of the dependence of the rotational speed of the turbocharger on the outside air temperature and flight altitude, the value of $n_{t c}$ is determined, which corresponds to the operating mode of the engines at this temperature. After take-off and acceleration at the minimum altitude to the most favorable speed, the helicopter is transferred to the continuous climb mode until the vertical speed of $0.5 \mathrm{~m} / \mathrm{s}$ or the limiting altitude is reached. The climb is performed at the most favorable speed when the engines are operating at a given mode, which is controlled according to the mode indicator up to an altitude of $2000 \mathrm{~m}$, and above the turbocharger revolutions, which are determined before takeoff.

During the climb, the pilot must accurately maintain the specified flight speeds, engine operating conditions and ensure that there is no slip.

Let's divide the resulting barogram of altitude into a number of uniform sections in time $\Delta \tau \approx 50 \mathrm{~s}$. The value of the vertical speed is calculated as the ratio of the difference between the next and previous ordinates of the barogram to the time interval:

$$
V_{y_{p}}=\Delta H_{p} / \Delta \tau \text {. }
$$

This data is used to build a dependence $V_{y_{C T}}=f(H)$. The climb time is determined by the method of numerical integration of the dependence $V_{y}=f(H)$, for which it is divided into a series of uniform heights $\Delta H \approx 500 \mathrm{~m}$, and the climb time is found for each of these intervals:

$$
\Delta \tau=\Delta H_{p} / V_{y_{a v}},
$$

where $V_{y_{w v}}$ - the average vertical speed in the height interval $\Delta H$.

Then the obtained time values are added to each other and a barogram of the climb time is built.

Before performing flights to determine the time $Q$ and kilometer $q$ fuel consumption, it is necessary to determine the flight mass of the helicopter, the capacity of the fuel system and the remaining fuel, which is not produced.

To determine $Q$ and $q$ fuel consumption, a series of modes is performed in horizontal flight at different speeds and flight altitudes - 5 flight altitudes 100, 1000, 2000, $3000,4000 \mathrm{~m}$ and 5-6 flight speeds in the range from $V_{r}^{\min }$ to $V_{r}^{\max }$. The duration of the test section of the flight is 2-3 min. The accuracy of keeping on the test section of the altitude, $\Delta H \pm 25 \mathrm{~m}$, speed $V_{p r} \pm 5 \mathrm{~km} / \mathrm{h}$. To keep constant the value of the reduced mass of the helicopter $m_{r}$ when performing horizontal discharge platforms at a given height, each next platform in speed is performed at a height determined by the formula:

$$
P_{n}=\frac{P_{0}\left(m_{e}+\rho W_{T}\right)}{m_{r}},
$$


where $m_{r}$ - given reduced mass, kg; $m_{e}$ - weight of equipped helicopter, kg; $\rho$ - fuel density, $\mathrm{kg} / \mathrm{cm}^{3} ; W_{T}$ - fuel volume in tanks, $1 ; P_{0}=760 \mathrm{~mm} \mathrm{Hg}$ - pressure in the ground under standard atmospheric conditions; $P_{n}$ - pressure at the corresponding flight altitude, $\mathrm{mm} \mathrm{Hg}$.

The value of the amount of fuel, during the production of which it is necessary to increase the height of the horizontal platform relative to the installed one by $25 \mathrm{~m}$, are given in Table 2 .

Table 2

Fuel consumption values for increasing the height of the horizontal platform relative to the set at $25 \mathrm{~m}$, depending on the flight weight at altitudes $H=100-4000 \mathrm{~m}$

\begin{tabular}{|c|c|c|c|c|c|}
\hline \multicolumn{7}{|c|}{ Average flight mass, $m_{f l . a v}, \mathrm{~kg}$} \\
\hline 11100 & 10600 & 10100 & 9000 & 8500 & 8000 \\
\hline \multicolumn{6}{|c|}{ Fuel consumption on mode, $\mathrm{d} m_{n} / \mathrm{d} W_{n}, \mathrm{~kg} / \mathrm{l}$} \\
\hline $35 / 46$ & $34 / 44$ & $33 / 43$ & $29 / 38$ & $28 / 36$ & $26 / 34$ \\
\hline
\end{tabular}

According to the records, when performing horizontal consumable platforms, fuel consumption is determined:

$$
\begin{aligned}
& Q_{p r}=Q_{\phi} \frac{760}{p_{n}} \sqrt{\frac{288}{T_{n}}} ; V_{p r v}=V_{i} \sqrt{352 \frac{288}{p_{n}}} ; \\
& q_{p r}=\frac{Q_{p r}}{V_{p r v}} ; \vec{q}=\frac{q_{p r}}{m_{p r}}=\frac{Q_{p r}}{m_{p r} V_{p r o}}=\frac{Q}{m V},
\end{aligned}
$$

where $Q_{r}$ - reduced time fuel consumption, $\mathrm{kg} / \mathrm{h} ; Q_{a}-$ actual time fuel consumption, obtained during the tests, $\mathrm{kg} / \mathrm{h}$; $V_{r}$ - reduced flight speed, $\mathrm{km} / \mathrm{h} ; V_{i}$ - indicated flight speed, $\mathrm{km} / \mathrm{h} ; q_{i}-$ reduced kilometer fuel consumption, $\mathrm{kg} / \mathrm{km}$; $\vec{q}$ - relative reduced kilometer fuel consumption, $\mathrm{kg} / \mathrm{km}$; $T_{n}$ - outdoor temperature, $\mathrm{K}$.

Next, generalized characteristics of fuel consumption $Q_{r}=f\left(V_{r}\right)$ and $\vec{q}=f\left(V_{r}\right)$ are built for a number of values $m_{r}=$ const, from which it is then possible to determine the time $Q$ and kilometer $q$ fuel consumption for any given flight conditions, that is, for any values $m, V$ and $T_{n}$. For this, in accordance with the values of a given flight mass $m$ and a given flight altitude $P_{f a}$, calculate $m_{r}$ :

$$
m_{r}=\frac{p_{0}}{p_{n}} m,
$$

and then in accordance with the dependencies $\vec{q}=f\left(V_{r}\right) \vec{q}$ are determined, then by the formula:

$$
q_{3}=\vec{q} m_{3}, Q_{3}=q_{3} V_{r} \sqrt{\frac{T_{f a}}{T_{0}}},
$$

let's calculate the actual value of the time $Q$ and kilometer $q$ fuel consumption in the given conditions.

The value $V_{i}=V_{r} \sqrt{\frac{0.00284 p_{n}}{T_{0}}}$ is used to determine the indicated speed $V_{r}$ and build dependencies $q=f\left(V_{r}\right), q=f\left(V_{r}\right)$, $Q=f\left(V_{r}\right)$ for the given values $m, H$ and $T_{f a}$.

5.2.4. Checking the sufficiency of gas dynamic stability reserves. The stability check of the power plant $(\mathrm{PP})$ of the Mi-8MSB-V helicopter, which includes the TV3-117VMASBM1V 4E series turboshaft engines, is performed in ac- cordance with the following classification when installing the SED set:

a) PP operates steadily;

b) PP does not operate stably if it starts:

- engine surge, which is accompanied by an increase

in the gas temperature behind the turbine or unauthorized engine shutdown;

- unauthorized extinguishing of the main combustion chamber.

The basis for making an appropriate decision in this case is the Report of the Motor Sich Joint Stock Company (Zaporizhzhia, Ukraine) on the results of tests to verify the reliability of the control system with imitation of the required amount of surge of a given intensity per resource.

The indicators characterizing the operation of the engine on the ground and in flight in constant and transient modes are:

- common pitch of the main rotor;

- mode with the IR-117 measurement sensor;

- the number of revolutions of the turbocharger;

- the number of revolutions of the rotor;

- gas temperature behind the turbine;

- oil pressure in the engine;

- oil temperature at the engine outlet;

- vibration level of the engine housing and its units.

The criterion that characterizes the stability of the PP operation when using the SED set are:

$$
\delta \pi_{k}^{*}=\frac{\pi_{w e s}^{*}-\pi_{o m}^{*}}{\pi_{o m}^{*}}
$$

where $\pi_{z s}^{*}$ - degree of total pressure increase by the compressor on the verge of stability; $\pi_{o m}^{*}$ - degree of total pressure increase by the compressor on the line of operating modes.

5.2.5. Check of operational parameters and an estimation of engine operation with the SED set. At this stage, determine the operating parameters of the engines in the suspension mode when operating engines with a takeoff weight of 9000-11100 kg and a wind speed of not more than $5 \mathrm{~m} / \mathrm{s}$. Determination of the operating parameters of the engines during horizontal flight is carried out at altitudes up to $2000 \mathrm{~m}$ at speeds up to $V_{r}=250 \mathrm{~km} / \mathrm{h}$.

Determination of the operating parameters of the engines when lowering the helicopter is carried out on the modes of vertical descent from a height of not more than $200 \mathrm{~m}$ with running engines, engine planning in the allowable FOM range of vertical descent speeds and instrument flight speeds. At vertical descent from height of $200 \mathrm{~m}$ to $20 \mathrm{~m}$ not to allow speed of decrease more than $5 \mathrm{~m} / \mathrm{s}$, and from height of $20 \mathrm{~m}$ to $10 \mathrm{~m}$ - no more than $3 \mathrm{~m} / \mathrm{s}$, and below $10 \mathrm{~m}$ to reduce speed of decrease so that by the time of landing it was not more than $0.2 \mathrm{~m} / \mathrm{s}$.

The operating parameters of the engines must meet the FOM requirements of the Mi-8MSB-V helicopter and the FOM of the TV3-117VMA-SBM1V 4E series engines.

5.2.6. The initial data for the processing of OMI materials is the calibration characteristics of the measuring OMI channels on the Mi-8MSB-V helicopter. The transformation of parametric information is carried out using special hardware and software. The results of the OMI processing are presented in the form of tables or graphs of the dependence of the registered parameters on the function 
of time. The volume, shape and scale of the graphs are indicated in the task for the OMI processing.

Based on the results of ground tests, the values of the main parameters of the engine operation are recorded, which lead to standard atmospheric conditions and are compared with the results of control bench tests from the engine logs. They are also compared with the values that are recommended by the MTO of the TV3-117VMA-SBM1V 4E series engine, the MTO of the Mi-8MSB-V helicopter and the technical specifications of the SED set. A comparative analysis of the results obtained can be carried out using a tabular or graphical method, with the construction of the throttle characteristics of the engine:

$$
\begin{aligned}
& \pi_{k}, T_{\mathrm{H} . \mathrm{r}^{0}}=f\left(n_{n T C . \mathrm{R}}\right) \text { or } \\
& n_{n T C}, T_{\mathrm{H} . \mathrm{R}^{0}}=f\left(\pi_{k}\right) .
\end{aligned}
$$

On the basis of a comparative analysis, it is concluded that the results obtained are responsible for the MTO requirements of the TV3117VMA-SBM1V 4E series engine and the MTO of the Mi-8MSB-V helicopter.

Processing, analysis and evaluation of test results is carried out at each stage of ground and flight tests.

The order of processing, analysis, evaluation of test results and the form of presentation of the results obtained is determined by the type and technical characteristics of the information processing tools used, as well as the adopted algorithms and processing methods. This procedure requires detailed study at the stage of preparation of the flight task.

Pre-processing, analysis and evaluation of test results are carried out at the site of ground operations and during flight tests.

\section{Research results}

The application of the developed technique in practice made it possible to obtain important data; subsequently, the structure of energy losses in the mixing chamber and diffuser was characterized. The developed method of flight tests of the SED set made it possible to check the performance of a particular sample in all important flight modes. The technique makes it possible to determine, by the OMI parameters, the fuel consumption at different operating modes of the PP and to obtain a qualitative characteristic of

$\mathrm{H}$---barometric altitude the fuel consumption in the case with and without a SED set installed on board. An example of the representation of the OMI parametric information is shown in Fig. 4 without a SED set installed on board and with an installed one (Fig. 5).

The most important and regulated SED indicator is the loss of power of the engine on which it is installed. The technique allows to experimentally obtain these data.

Fig. 6 shows a general SED view, which was tested as part of the Mi-8MSB-V helicopter.

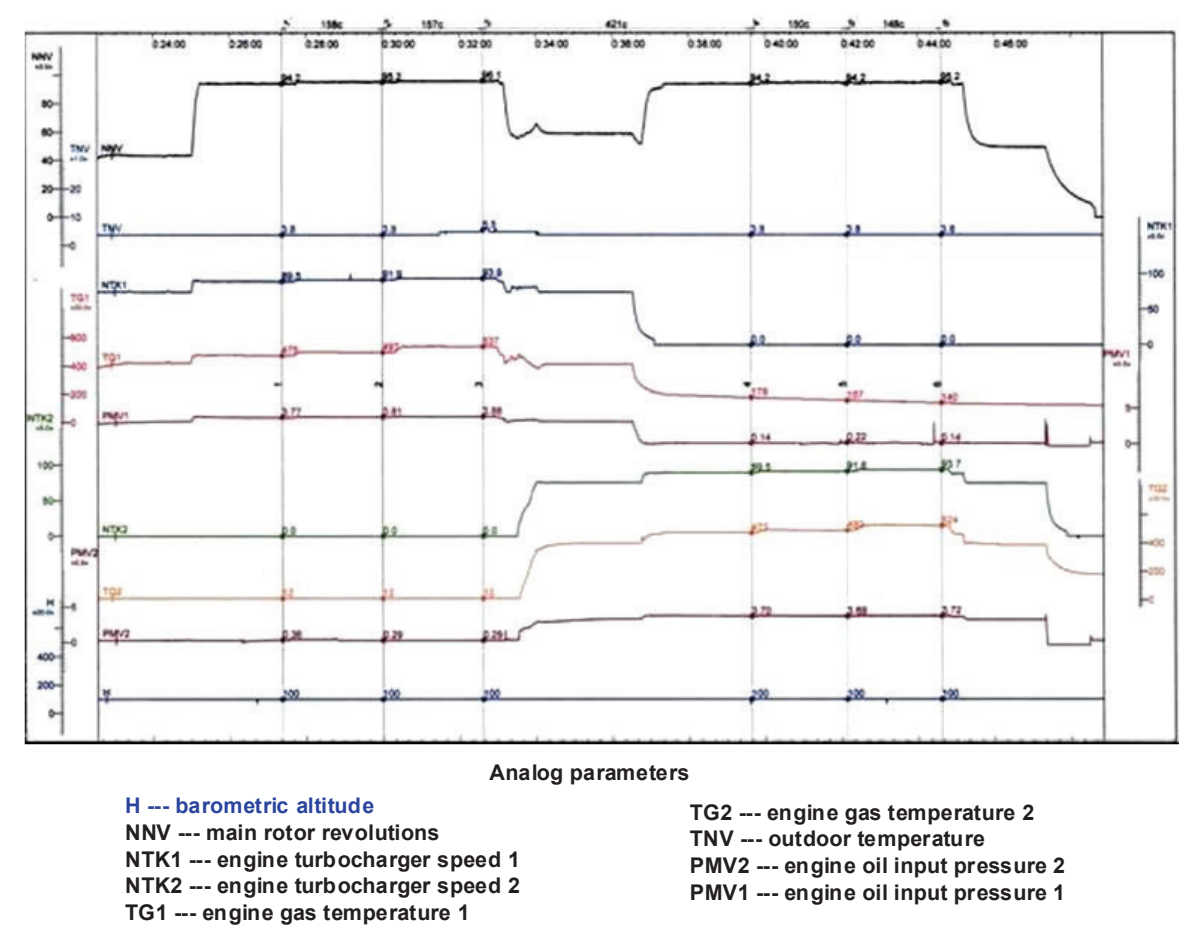

Fig. 4. Parametric information of on-board measurement equipment of a helicopter without an installed set of screen-exhaust devices

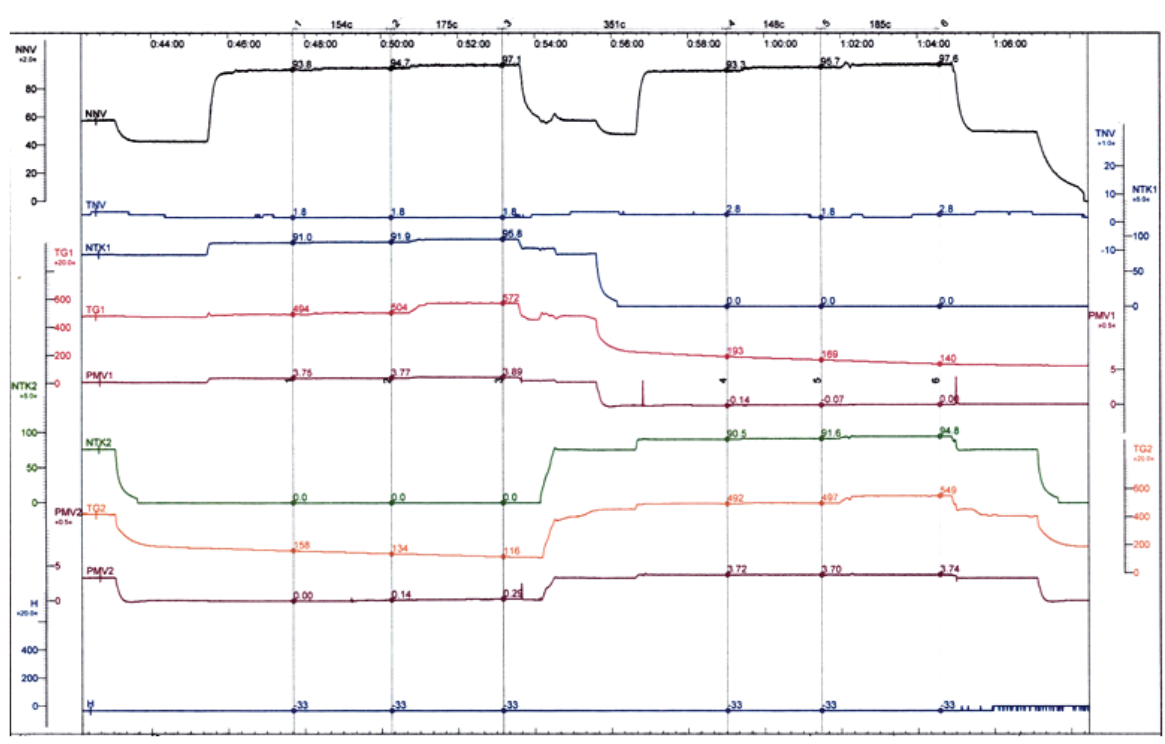

NNV---main rotor revolutions

Analog parameters

NTK1---engine turb ocharger speed 1

NTK2---engine turbocharger speed 2

TG1---engine gas temperature 1

TG2---engine gas temperature 2

TNV---outdoor temperature

PMV2--- engine oil input pressure 2

PMV1--- engine oil input pressure 1

Fig. 5. Parametric information of on-board measurement equipment of a helicopter with an installed set of screen-exhaust devices 


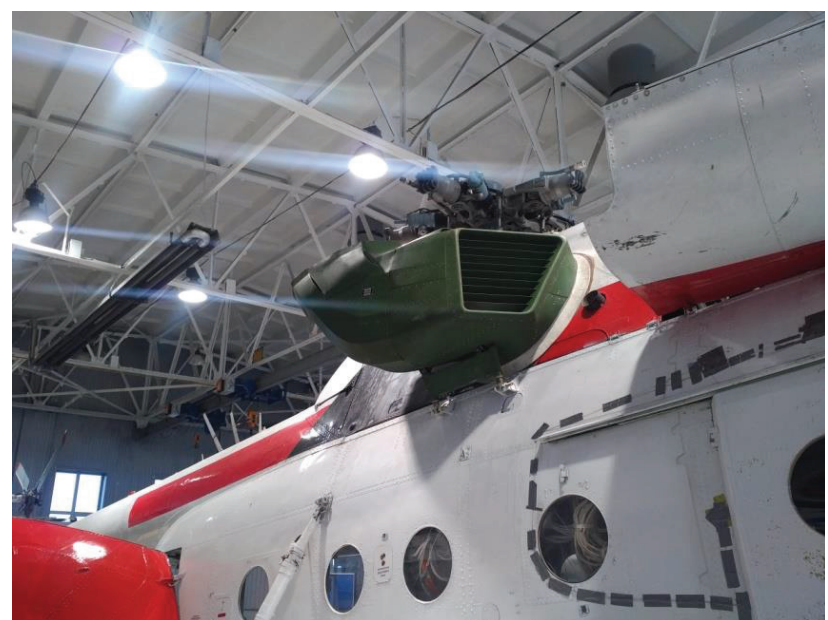

Fig. 6. General view of the screen-exhaust device, which was tested as part of the Mi-8MSB-V helicopter

Based on the results of the study and testing of this SED, a decision was made on the basis of the obtained and analyzed results to refine its flow path - to take constructive measures in order to optimize the parameters of internal gas dynamics.

The technique developed by the author made it possible to carry out all the necessary research and obtain reliable information during the experiment.

\section{SWOT analysis of research results}

Strenghts. The developed test and research technique allows obtaining detailed characteristics of the SED sets installed on the helicopter. The developed complex for calculating the fuel consumption of an engine with and without an installed SED makes it possible to obtain comparative characteristics when using various types of SEDs.

Weaknesses. The use of this technique is economically costly, given the cost of fuels and lubricants and the need to organize work to conduct flight tests.

Opportunities. Based on the results of the application of this technique, it is possible to make a decision on further modernization of the SED design, optimization of the parameters of internal aerodynamics in order to reduce energy losses.

Threats. The need to attract qualified test pilots to the study, and to carry out all the necessary measures to ensure flight safety.

\section{Conclusions}

1. Modern methods and instruments for measuring the level of infrared radiation are analyzed. Selected devices with the measurement range and sensitivity necessary to ensure research, taking into account the infrared radiation of the homing head of an air-to-air missile of the R-60 type (with a sensitivity in the wavelength range $\Delta \lambda=2.8-4.2 \mu \mathrm{m})$. A set of parameters and their characteristics of standard on-board measurement tools for determining the amount of power loss on the shaft of a free turbine of a helicopter GTE have been determined. Based on the results of the conducted SED tests, qualitative and quantitative parametric information was obtained in digital and graphic form.
2. A test procedure for a set of screen-exhaust devices as part of the Mi-8MSB-V helicopter has been developed. It allows to determine the level of engine power losses in various operating modes by the parameters of the onboard information collection devices in different operating modes when working with SED. This makes it possible to obtain a characteristic of fuel consumption in the case of a set of screen-exhaust devices installed on board and without it. The technique takes into account the possibility of simultaneously conducting both flight and ground SED tests to construct an infrared radiation indicatrix and determine the distances and angles of target capture by the homing head of portable anti-aircraft missile systems.

\section{References}

1. Kulyk, M. S., Arkhipov, M. I., Hrekov, P. I. et. al; Kulyk, M. S. (Ed.) (2013). Dozvukovi hazovi ezhektory ekranno-vykhlopnykh prystroiv HTD. Kyiv: Nats.avia un-t, 142.

2. Kataloh zapchastei $M y-8$ (2020). OOO Vertol. Available at: http://vertol.com.ua/product/katalog-zapchastey-mi-8\#slide4-field_prod image-102

3. Na vooruzhenie VSU priniaty kombinirovannoe ustroistvo vybrosa «ADROS» KUV 26-50-0 i ekranno-vykhlopnoe ustroistvo «ADROS» $A S H-01 \mathrm{~V}$ (2017). Krylia vse ob ukrainskoi aviatsii. Available at: http://www.wing.com.ua/content/view/17611/36/

4. Sheliakin, O. M., Borysiuk, O. P., Shein, I. V. (2016). Obgruntuvannia alhorytmychnykh zavdan suchasnykh analitychnykh zasobiv bortovoho kompleksu oborony litalnykh aparativ. Kharkivskyi Universytet Povitrianykh Syl, 46-50.

5. Marynowski, T., Desevaux, P., Mercadier, Y. (2009). An Investigation of Ejector Design by CFD Modelling. International Journal of Turbo and Jet Engines, 26 (1), 61-78. doi: http:// doi.org/10.1515/tjj.2009.26.1.61

6. Zhang, J., Pan, C., Shan, Y. (2014). Progress in helicopter infrared signature suppression. Chinese Journal of Aeronautics, 27 (2), 189-199. doi: http://doi.org/10.1016/j.cja.2014.02.007

7. Zhou, Z., Huang, J., Wang, J. (2019). Radar/infrared integrated stealth optimization design of helicopter engine intake and exhaust system. Aerospace Science and Technology, 95, 105483. doi: http://doi.org/10.1016/j.ast.2019.105483

8. Rohacs, J., Jankovics, I., Gal, I., Bakunowicz, J., Mingione, G., Carozza, A. (2018). Small Aircraft Infrared Radiation Measurements Supporting the Engine Airframe Aero-thermal Integration. Periodica Polytechnica Transportation Engineering, 47 (1), 51-63. doi: http://doi.org/10.3311/pptr.11514

9. Mahulikar, S. P., Rao, G. A., Sane, S. K., Marathe, A. G. (2005) Aircraft Plume Infrared Signature in Nonafterburning Mode. Journal of Thermophysics and Heat Transfer, 19 (3), 413-415. doi: http://doi.org/10.2514/1.14686

10. Mahulikar, S. P., Prasad, H. S. S., Potnuru, S. K. (2008). Infrared Signature Suppression of Helicopter Engine Duct Based on «Conceal and Camouflage». Journal of Propulsion and Power, 24 (3), 613-618. doi: http://doi.org/10.2514/1.28636

11. Jackson, K. E. (2018). Advances in Rotorcraft Crashworthiness: Trends Leading to Improved Survivability 37th Alexander A. Nikolsky Honorary Lecture. Journal of the American Helicopter Society, 63 (2), 1-25. doi: http://doi.org/10.4050/jahs.63.021001

12. Kapitanchuk, K. I., Hrekov, P. I., Andriishyn, M. P., Andriishyn, N. M. (2015). Kharakterystyky hazovoho ezhektora yak elementa vykhidnoho prystroiu. Promyslova hidravlika $i$ pnevmatyka. Vinnytsia: «HLOBUS-PRES», 165-166.

13. Kapitanchuk, K. I. (2017). Sertyfikatsiini nazemni vyprobuvannia ekranno-vykhlopnoho prystroiu vertolotu. Promyslova hidravlika i pnevmatyka. Vinnytsia: «HLOBUS-PRES», 123-124.

Kinaschuk Mykhailo, Postgraduate Student, Department of Aircraft Engines, National Aviation University, Kyiv, Ukraine, ORCID: http:// orcid.org/0000-0002-7130-8470, e-mail: kinaschukm.i@gmail.com 